\title{
Self-reported TPACK of teacher educators across six countries in Asia and Europe
}

\author{
Jérémy Castéra $^{1 *}$, Claire Coiffard Marre ${ }^{1}$, Margaret Chan Kit Yok ${ }^{2}$, Kezang Sherab ${ }^{3}$, Maria Antonietta \\ Impedovo $^{1}$, Tago Sarapuu ${ }^{4}$, Alice Delserieys Pedregosa ${ }^{1}$, Sufiana Khatoon Malik ${ }^{5}$, Hélène Armand ${ }^{1}$ \\ ${ }^{1}$ Aix-Marseille Université, ADEF, Marseille, France; ${ }^{2}$ Universiti Teknologi MARA, Malaysia; ${ }^{3}$ Royal \\ University of Bhutan; ${ }^{4}$ Tallinn University, Estonia, ${ }^{5}$ Faculty of Social Sciences National University of Modern \\ Languages, Islamabad, Pakistan
}

* Corresponding author: jeremy.castera@univ-amu.fr; +33(0)4 13550288

\begin{abstract}
The initial technological pedagogical and content knowledge (TPACK) model was theorised on seven clearly identified factors. However, many studies have failed to empirically identify these seven factors, and elements influencing TPACK level, such as national context, gender, and age, remain unclear. The study is focused on teacher educators' TPACK as one of the most important elements in schoolteacher training. The main goals were to test the validity of the initial TPACK seven-factor model in a cross-national analysis context and to identify factors influencing the TPACK perception. The sample was composed of 574 teacher educators coming from a total of eight schools of educational institutions from six countries. A 26-item questionnaire, based on a four-point Likert scale, investigated the seven factors of the TPACK model as independent scales. It was administered online and anonymously. A confirmatory factor analysis using the robust maximum likelihood method and Kruskal-Wallis chi-squared tests were performed. The study showed four major results: 1) a relative stability of the seven-factor model structure across countries; 2) the relative differences of university teachers' TPACK perceptions across six countries in Europe and Asia; 3) the dependence of age and TPACK factors; and 4) an independence of gender/academic level and TPACK.
\end{abstract}

Keywords: $\quad$ TPACK, $\quad$ cross-national study, university teachers, CFA

\section{Acknowledgment}

The project 'Blended Learning Courses for teacher educators between Asia and Europe' ( $n^{\circ}$ : 574130-EPP-12016-1-FR-EPPKA2-CBHE-JP) is supported by the European Commission Education, Audiovisual and Culture Executive Agency (EACEA) - Erasmus+ Higher Education - International Capacity Building programme. 


\section{Introduction}

Recent literature highlighted the importance of developing teachers' technological pedagogical and content knowledge (TPACK) for technology integration in teacher training programmes (Byker et al. 2018; Joo et al. 2018; Chen and Jang 2018; etc.). Indeed, in the 21st century, an effective teacher needs to know how to integrate technology into teaching (Niess 2011; Benton-Borghi 2013). The TPACK model proposed by Mishra and Koehler (2006) can be used to investigate teachers' knowledge for improving teacher training. The study is focused on teacher educators' TPACK as one of the most important elements in schoolteacher training. It has been shown that most educators believed that the successful integration of technology into classrooms is an easy task requiring merely technology skills (Benson and Ward 2013; Schmidt and Gurbo 2008). However, developing TPACK is fundamental for teachers and educators to implement technology in courses not merely focused on technology skills. Voogt and McKenney (2017), stated that it enables teachers to select and use hardware and software, identify the affordances (or lack thereof) of specific features and use the tools in pedagogically appropriate and effective ways. In this study, the seven-factor model based on Mishra and Koehler (2006) was used to analyse 574 teacher educators across six countries. A preliminary analysis indicated the results were consistent with this theoretical model. Thus, the objective was to investigate the possible links between educators' TPACK perception and demographic factors, such as gender, age, level of academic degree and country ("demographic factors" is used in its widely accepted definition, e.g. Baturay and Toker 2015; Griffiths et al. 2004...).

\section{Theoretical background}

\subsection{TPACK model}

Mishra and Koehler (2006) theorised the TPACK model by adding a third dimension related to technological knowledge (TK) to Shulman's model (Shulman 1987), which was based on two dimensions related to pedagogical knowledge (PK) and content knowledge (CK). Consequently, the three overlapping dimensions were formed logically into a seven-factor model, taking into account these three basic dimensions (TK, PK, and $\mathrm{CK}$ ) and the interactions among them: technological content knowledge (TCK), technological pedagogical knowledge (TPK), pedagogical content knowledge (PCK), and technological pedagogical content knowledge (TPCK). This theoretical framework emerged from many empirical works and practical applications (Koehler and Mishra 2005; Koehler et al. 2004; Koehler et al. 2007). However, other empirical studies failed to support these seven initial factors. Luik et al. (2018) reported that the model measured three main factors within a preservice teacher sample: technology (T-factors, grouping all the factors linked to technology: TK, TPK, TCK, and TPACK), pedagogy (PK and PCK), and content (CK). Similarly, Cubeles and Riu (2018) validated a threefactor model with a sample of 113 university teachers: TK as the first factor, PK/PCK as the second, and TCK/TPK/TPCK as the third. They concluded that the number and the type of TPACK factors depended on the investigated population. This work is fully compliant with the study of Schmidt et al. (2009), who found that Tfactors were merged in only one T-factor except TK, which was still an independent factor in their study. Furthermore, Koh et al. (2010) described another type of construct: a five-dimension model consisting of TK, CK, knowledge of pedagogy, knowledge of teaching with technology, and knowledge from critical reflection for a Singaporean preservice-teacher sample. The main pitfall of the seven-factor model is the construct validity dependence regarding the tool used (generally a questionnaire) and the population sampled (which is context dependent). Archambault and Barnett (2010) highlighted the challenge of creating an instrument which can be generalizable to every context and every subject-matter to be taught. Considering teaching as a complex and illstructured domain (Koehler and Mishra 2009), the Mishra and Koehler's ideal model can be adapted to each learning context minimizing risk of misinterpretation of the results through of a non-adequate model. This precaution is usually taken by researchers in order to provide an adequate response to the learning situation investigated in terms of training remediation for instance. Therefore, clarifying the structure of the model is greatly recommended for any new population and context investigated, especially when a cross-national sample is investigated. 
There are alternative or complementary models to TPACK that can be used to analyse technology integration in pedagogical contexts. The SAMR model describes technology integration in pedagogical context as a fourlevel-framework starting from the lowest efficiency (substitution) to highest (redefinition) of integration (Puentedura 2013). Another framework, probably even more interesting in terms of research potentialities, is the TPR \& A (Technological Pedagogical Reasoning and Action: Harris and Phillips 2018). This framework is based on the Shulman's model (Shulman 1987) of Pedagogical Reasoning and Action (PR \& A) which argues that any educational decision and action is related to knowledge-based PR \& A. The knowledge dimensions of $\mathrm{PR} \& \mathrm{R}$ are comprehension, transformation (including preparation, representation, selection, and adaptation/tailoring to student characteristics), reflection, and new comprehension (Harris and Phillips 2018). Harris and Hofer (2010) demonstrated the high potentiality of this idea by reaching the challenge of developing in-service and pre-service teachers' TPACK through that they called Learning Activity Types (LAT) which is based on the TPR \& A model. However, the TPACK model was chosen as the framework guiding this particular study to ensure the best fitting with the purpose of the research goals.

\subsection{Demographic factors influencing individual TPACK}

Koh et al. (2010) revealed the importance of the gender factor in the TPACK perceptions of pre-service students. This study is consistent with other studies like that of Markauskaite (2006), who showed that male teachers are more confident in using computers than their female colleagues; Lin et al. (2013), who found higher PK for female teachers but lower TK; and Scherer et al. (2017), who found that for all the T-factors, males report higher competency than females. However, thinking gender as predictor of TPACK can be interpreted as an essentialist view of the knowledge determinants. Obviously, there is no biological reason to explain the observed knowledge differences between males and females. The differences are rooted in social context where males and females are placed in. Generally, studies report gender differences without giving any explanation giving more room for essentialist interpretation. One goal of this study was to see if males and females are different in their self-reporting TPACK and if it is possible to relate the differences to other dependent demographic factors.

Knowledge dimensions, including technology, are dependent on demographic factors, such as age and teaching experience. A negative correlation between age and dimensions including technology has been confirmed (Koh et al. 2010; Lin et al. 2013; Lee and Tsai 2010). Nevertheless, Guo et al. (2008) reported that there was no statistically significant difference with respect to technology competence among different age-groups of preservice teachers. Nevertheless, Hofer and Harris (2017) highlighted the need of differentiating preservice TPACK-based training module for more experimented teachers. This is in complete agreement with the work of Lee and Tsai (2010) or Yaghi (2001) who showed empirically that more teachers have experience, lower they are confident with their TPACK. Age and teaching experience are two strongly dependant factors which are difficult to clearly separate: the very large majority of experienced teachers are at the same time the oldest. Notwithstanding, a factor generally not tested in TPACK studies is how the level of academic degree of teachers/educators can influence TPACK perceptions. Considering this lack of information, another goal of this study was to make this possible relationship clearer. Moreover, the targeted samples usually included mainly pre-service and in-service teachers (e.g., Bueno-Alastuey et al. 2018; Cengiz 2015; Koh et al. 2010; Lee and Tsai 2010; Luik et al. 2018; Lin et al. 2013), and very few studies have investigated university teachers (e.g., Cubeles and Riu 2018). Therefore, this study aims to clarify the structure of the TPACK model based on an international university teacher sample and to report the elements influencing TPACK, such as national context, gender, level of academic degree and age.

As suggested by Khine et al. (2017), many studies have been carried out in different national contexts, but very few of them investigated the national and cultural context as a possible element influencing TPACK. For instance, Chang et al. (2015) explored the TPACK perceptions of two physics instructors from China and Taiwan. They found TPACK differences attributed to the national teaching context, but this case study is not generalisable. Chai et al. (2013) reported that the TPACK results of pre-service teachers from China, Hong Kong, Singapore, and Taiwan were dependent on the national context, but without specifying the findings. Overall, many researchers have investigated TPACK in separate national contexts and rarely from a cross- 
national perspective, meaning that comparatively little is known about the significance of the model in crossnational research contexts. This lack of data is probably rooted into the interpretation issues of cross-national studies. Given some relevant elements of countries' contexts is necessary in order to formulate explaining hypotheses and results' interpretation. Thus, the French tradition of "didactique", which is based on a framework very similar to the PCK model of Shulman, has been very present into the teacher training since decades reflecting (the work of Chevallard 1985). More generally, in Europe, research in education is quite old, for instance The European Association for Research on Learning and Instruction (EARLI) was born in 1985. Concerning the Asian countries, the context is much more different: in Bhutan (VanBalkom and Sherman 2010) and in Pakistan (Khatoon Malik and Tanzeela 2012) researchers noticed major problems such as the low quality of teacher training programs, lack of research and innovations. Nonetheless, Malaysia is very active considering educational innovations, for instance the Universiti Teknologi MARA has embarked on i-Learn Center since 2005 to encourage Blended learning in the educational system. In addition, since 2018, the programme 'Week without Walls@ UiTM Sarawak' provides option to lecturers to implement 100\% online studies with experts from industries or other universities. Furthermore, all the institutions involved in this study are part of an international blended learning project since 2016 (BLTeae: Blended Learning for teacher Educators in Asia and Europe) indicating an increasing will of developing teacher educators' skills in Asia and Europe.

Another element which can be very informative is the "use sub-index" of the IDI (ICT development index) that gives information about the population level about how they are able to use ICT. The ranking separate clearly European countries from Asian countries of this sample: Denmark $\left(1^{\text {st }}\right)$ Estonia $\left(15^{\text {th }}\right)$, France $\left(17^{\text {th }}\right)$, Malaysia $\left(48^{\text {th }}\right)$, Bhutan $\left(114^{\text {th }}\right)$ and Pakistan $\left(152^{\text {nd }}\right)^{1}$. This indicator is not specifically related to teachers, but it gives an opportunity to appreciate a general trend.

\section{Rationale and research questions}

The original TPACK seven-factor model of Mishra and Koehler (2006) has recently been called into question by empirical studies. It seems that the number of factors is linked to some specific contexts of studies. In this respect, this study investigated the robustness of the seven-factor model in the context of international comparison. The constancy of the seven-factor model in a cross-national perspective would give some support for using this model in further cross-national investigation. Moreover, despite the profusion of studies was based on primary and secondary school teachers, there is a lack of knowledge about factors influencing university teachers' TPACK.

Hence, this study aims to explore this field by attempting to answer the following questions:

1. Are university teachers' perceptions of technological, pedagogical, and content knowledge in six countries compatible with the seven-factor TPACK model?

2. To what extent are the seven TPACK factors related to university teachers' demographic factors? The hypotheses were that demographic factors, often reported at local level (gender, age and level of academic degree), would affect TPACK perception of an international teacher educators' sample. However, it was assumed that the national context would contribute globally more than the other factors to their TPACK perception.

\section{Methodology}

\subsection{Instrument}

The survey tool is based on the work of Lin et al. (2013), who developed a questionnaire for assessing pre- and in-service Singaporean science teachers' perceptions of technological pedagogical content knowledge. The questionnaire composed of different sections aiming to measure various constructs developed into the original seven-factor model (Mishra and Koehler 2006): TK, PK, CK, TPK, TCK, PCK, and TPCK (Table 1). The questionnaire was originally developed to assess science teachers' TPACK perception. Thus, a few changes were made in order to extend the sample to non-science teacher educators. For instance, in the original tool, the

\footnotetext{
${ }^{1}$ https://www.itu.int/net4/ITU-D/idi/2017/index.html\#idi2017rank-tab
} 
first item was: I have sufficient knowledge of science. In the newly extended questionnaire, this item has been modified: I have sufficient knowledge of the subject matter I teach.

A section of the questionnaire was devoted to collecting demographic factors: age (20-29, 30-39, 40-49, 50-59, $60-69$, or 70+), gender, and highest academic level (high school, bachelor, master, or $\mathrm{PhD}$ ).

After the first modifications, the questionnaire was piloted in all the countries on a small sample of teacher educators to verify its comprehension. It was followed by short interviews with the piloted respondents to identify possible issues. However, no change was made to items during this phase, since the respondents estimated the item comprehension as satisfactory. The online questionnaire was administered in English by email in all the institutions involved, except in France, where it was translated and thereafter validated with back-translation before the final sampling. The translation was made in France in order to ensure a high response rate in an institution where English is rarely used to disseminate information.

\subsection{Participants}

The sample consisted of 574 university teachers providing courses for students trained to be primary or secondary school teachers from eight institutions across six countries. The institutions were the Royal University of Bhutan (Bhutan), Alborg University (Denmark), Tallinn University (Estonia), the Université d'Aix-Marseille (France), the Universiti Teknologi MARA (Malaysia), the Institut Pendidikan Guru (Malaysia), the National University of Modern Languages (Pakistan), and the International Islamic University (Pakistan). All the institutions had been selected because they were all involved in different initiatives using educational technology (such MOOC, Blended-learning, etc.). Moreover, all these institutions formed the consortium participating in the BLTeae project (Blended Learning for Teacher Educators in Asia and Europe) funded by the European Commission. As anticipated and due to the noticeable attention taken to select the participating institutions, more than $98 \%$ of the sample reported the use of technologies at least once a day.

The institutions were very similar in terms of trained student profiles. The Royal University of Bhutan offers a four-year Bachelor of Education and one-year postgraduate programmes. Post-graduate programmes to train teachers are as well offered in France and in Estonia (Master level) whereas, in Pakistan, the institutions offer four-year bachelor programmes for the students like in Denmark and Malaysia. In addition, in Malaysia, it is possible to apply for an additional one-year postgraduate programme.

\subsection{Sampling scheme and data collection}

The questionnaire was administered following the same protocol in all institutions. The university teachers were invited through emails to respond to an online survey. All the data were collected anonymously between June 2017 and December 2017.

To address the research questions, the TPACK section, aiming to measure respondents' perceptions about TPACK, and the personal data section (e.g., age, gender, and academic background) were analysed and interpreted. The TPACK section had already been validated, since it was adapted from the work of Lin et al. (2013) to be in ad equation with a large range of university teachers' profiles, with only one question excluded from the original questionnaire. The 26 items were based on a four-point Likert scale (from strongly disagree to strongly agree) and investigated seven factors of the TPACK model as independent scales, as initially defined by Mishra and Koehler (2006). Table 1 shows items and their factors' contributions. The raw Cronbach alphas were calculated for each factor and showed good internal consistency $(>0.8)$, except for the PCK factor (between 0.6 and 0.7), which was, however, acceptable (Manerikar and Manerikar 2015). Specifically, these results support the seven-factor model with an acceptable reliability for each scale.

Table 1: Item contributions to the seven-factor TPACK model and Cronbach alphas

Item

TPACK factor

Cronbach alpha

scale 
I can think about the content of what I teach like a subject matter expert.

I am able to develop a deeper understanding of the content of CK3 the subject matter I teach.

I am able to stretch my students' thinking by creating strategies.

I am able to help my students to monitor their own learning.

I am able to help my students to reflect on their learning strategies.

I am able to plan group activities for my students. group work.

Without using technology, I can address the common misconceptions my students have about the taught subject matter.

Without using technology, I can help my students to understand the content knowledge in various ways.

I have the technical skills to use computers effectively. technology. 
I am able to use technology to introduce my students to real- TPK16 world scenarios.

I am able to facilitate my students to use technology to plan TPK17 and monitor their own learning.

I am able to facilitate my students to use technology to construct different forms of knowledge representation.

I am able to facilitate my students to collaborate with each other using technology.

I can use the software that is created specifically for the TCK20 0.81 subject matter I teach (e.g., data loggers for science).

I know about the technologies that I have to use for research TCK21 on the content of the subject matter I teach.

I can use appropriate technologies (e.g., multimedia TCK22 resources, simulation) to represent the content of the subject matter I teach.

I can teach lessons that appropriately combine knowledge of TPC23 0.87 the subject matter, technologies, and teaching approaches.

I can select technologies to use in my classroom that enhance TPC24 what I teach, how I teach, and what students learn.

I can use strategies that combine knowledge of the subject TPC25 matter, technologies, and teaching approaches that I learned about in my coursework in my classroom.

I can provide leadership in helping others to coordinate the TPC26 use of knowledge of the subject matter, technologies, and teaching approaches in my university.

\subsection{Statistical analysis}

Based on the theoretical framework of TPACK (Mishra and Koehler 2006), the hypothesis of the perception of TPACK was structured according to the seven factors of the model. The goal was to test whether the collected data were consistent with the nature of the theoretical model. Accordingly, the fitting of the model was measured with confirmatory factor analysis (CFA) using the robust maximum likelihood method. The classic indicators were used to evaluate the model's goodness of fit: the relative chi-square, since the sample was greater than $200(\chi 2 / \mathrm{df}<5$; Wheaton et al. 1977); the root mean square error of approximation (RMSEA <0.08; 
Browne and Cudeck 1993); the adjusted goodness of fit index (AGFI > 0.9; Tanaka and Huba 1985); the standardised root mean square residual (SRMR <0.05; Cangur and Ercan 2015); and the comparative fit index (CFI >0.9; Bentler 1990). To address the objectives of the second research question, Kruskal-Wallis chi-squared tests were performed, since the measurements failed to meet the normality assumption. This was completed by post-hoc Wilcoxon signed rank tests to compare with adjusted p-values (Holm 1979), taking into account the problem of multiple comparisons. In addition, an ANOVA was performed to investigate the relative impact of the national context comparatively to the other factors tested (level of academic degree, gender, age and interactions between them). All the statistical analyses were computed through the use of the R software.

\section{Results}

\subsection{CFA confirming the seven-factor model}

CFA using the robust maximum likelihood method was performed on the TPACK variables in order to measure the seven-factor model's fitness. The CFA indicators are reported in Table 2. The chi-square value was significant; however, the sensitivity of the chi-square test to the large sample size (>200) made this result no longer relevant (Schermelleh-Engel et al. 2003), and the relative chi-square value was acceptable $\left(\chi^{2} / \mathrm{df}=4.2\right.$; less than 5). The other indicators indicated good fit: RMSEA <0.08 (Browne and Cudeck 1993); AGFI >0.9 (Tanaka and Huba 1985); SRMR <0.05 (Cangur and Ercan 2015); CFI >0.9 (Bentler 1990).

Table 2: Goodness of fit indices

\begin{tabular}{lllllll}
\hline$\chi^{2}$ & df & p value & RMSEA & AGFI & SRMR & CFI \\
\hline 1163.981 & 278.000 & .000 & 0.075 & 0.965 & 0.048 & 0.917 \\
\hline
\end{tabular}

\subsection{TPACK perceptions}

\subsubsection{Country differences}

The findings supported a relatively similar trend among countries. In each country the lower scores were generally related to T-factors (Table 3 ). 


\begin{tabular}{|c|c|c|c|c|c|c|c|c|}
\hline & \multirow[t]{2}{*}{$\mathrm{N}$} & \multicolumn{7}{|l|}{ Mean } \\
\hline & & $\mathrm{CK}$ & PK & PCK & TK & TPK & TCK & TPC \\
\hline Bhutan (Bh) & 80 & 84.88 & 808 & 69.38 & 64.69 & 61.25 & 59.31 & 64.94 \\
\hline Denmark (De) & 23 & 84.38 & 81.17 & 79.88 & 76.63 & 74.19 & 75.30 & 75.25 \\
\hline Estonia (Es) & 39 & 86.05 & 75.75 & 72.75 & 76.63 & 70.69 & 75.80 & 71.31 \\
\hline France $(\mathrm{Fr})$ & 72 & 85.63 & 80.67 & 81.63 & 70.50 & 67.69 & 72.05 & 69.88 \\
\hline Malaysia (Ma) & 164 & 82.47 & 81.71 & 76.25 & 71.31 & 72.88 & 70.56 & 74.06 \\
\hline Pakistan $(\mathrm{Pa})$ & 196 & 81.88 & 80.83 & 73.00 & 74.94 & 74.13 & 71.80 & 74.63 \\
\hline $\begin{array}{l}\text { p-value } \\
\text { Kruskal- } \\
\text { Wallis } \\
\end{array}$ & & 0.202 & 0.128 & 0.000 & 0.000 & 0.000 & 0.000 & 0.000 \\
\hline $\begin{array}{l}\text { Post-hoc } \\
\text { Wilcoxon } \\
\text { signed rank }\end{array}$ & & & & $\begin{array}{l}\text { Bh }<\text { De, } p= \\
0.026 \\
\text { Bh }<\text { Fr, } p=0.000 \\
\mathrm{Bh}<\mathrm{Ma}, \mathrm{p}= \\
0.022 \\
\mathrm{Fr}>\mathrm{Es}, \mathrm{p}=0.047 \\
\mathrm{Fr}>\mathrm{Pa}, \mathrm{p}=0.003\end{array}$ & $\begin{array}{l}\mathrm{Bh}<\mathrm{Es}, \mathrm{p}=0.000 \\
\mathrm{Bh}<\mathrm{Ma}, \mathrm{p}=0.007 \\
\mathrm{Bh}<\mathrm{Pa}, \mathrm{p}=0.000\end{array}$ & $\begin{array}{l}\mathrm{Bh}<\mathrm{De}, \mathrm{p}=0.015 \\
\mathrm{Bh}<\mathrm{Es}, \mathrm{p}=0.024 \\
\mathrm{Bh}<\mathrm{Ma}, \mathrm{p}= \\
0.000 \\
\mathrm{Bh}<\mathrm{Pa}, \mathrm{p}=0.000 \\
\mathrm{~Pa}>\mathrm{Fr} \mathrm{p}=0.038\end{array}$ & $\begin{array}{l}\mathrm{Bh}<\mathrm{De}, \mathrm{p}= \\
0.000 \\
\mathrm{Bh}<\mathrm{Es}, \mathrm{p}=0.000 \\
\mathrm{Bh}<\mathrm{Fr}, \mathrm{p}=0.000 \\
\mathrm{Bh}<\mathrm{Ma}, \mathrm{p}= \\
0.000 \\
\mathrm{Bh}<\mathrm{Pa}, \mathrm{p}=0.000\end{array}$ & $\begin{array}{l}\mathrm{Bh}<\mathrm{Ma}, \mathrm{p}= \\
0.000 \\
\mathrm{Bh}<\mathrm{Pa}, \mathrm{p}= \\
0.000\end{array}$ \\
\hline
\end{tabular}

Table 3: Seven factors' means among countries (all the factors have been rescaled to be out of 100). The significance is based on Kruskal-Wallis chi-squared tests, completed by post-hoc Wilcoxon signed rank tests.

However, there were strong differences between countries (Table 3) related to five factors: PCK $\left(\chi^{2}(5)=28.74\right.$ ); TK $\left(\chi^{2}(5)=34.40\right)$; TPK $\left(\chi^{2}(5)=48.97\right)$; TCK $\left(\chi^{2}(5)=46.16\right)$; TPC $\left(\chi^{2}(5)=33.38\right)$. The differences were mainly related to the scores of the Bhutanese sample, which were lower than many of the other countries. More specifically and concerning the PCK factor, the post-hoc Wilcoxon signed rank test indicated that the sample from Bhutan had significantly lower results regarding PCK than Denmark $(p=0.026)$, France $(p=0.000)$, and Malaysia $(p=0.022)$, whereas the French sample had significantly higher results than Estonia $(p=0.047)$ and Pakistan ( $p=0.003)$. The same trend was observed considering the TK, TPK, TCK, and TPC factors: Bhutan had lower scores than the majority of countries. As shown in Table 3, the Bhutanese sample showed significantly lower results regarding TK factors compared to Estonia $(p=0.000)$, Malaysia $(p=0.007)$, and Pakistan ( $p=0.000)$. It was also observed that on the TPK scale, the French sample $(M=67.69)$ had the second lowest score after Bhutan, which was significantly lower than Pakistan's score ( $\mathrm{p}=0.038)$.

\subsubsection{Age differences}

Age, among the demographic factors, was hypothesised to be related to TPACK perceptions. Table 4 illustrates a positive and gradual evolution of mean scores of factors CK, PK, and PCK from the youngest age group to the oldest age group. There were score differences of $8 \%(\mathrm{CK}), 5 \%(\mathrm{PK})$, and $7 \%(\mathrm{PCK})$ between the youngest group and the oldest group. The Kruskal-Wallis chi-squared tests showed significant variations between age groups for CK $(\mathrm{p}=0.025)$ and PCK $(\mathrm{p}=0.018)$. Nevertheless, the post-hoc test did not show any significant difference between groups.

Conversely, it was indicated that factors including technology (TK, TPK, TCK, and TPC) gradually decreased from the youngest group to the oldest (significant Kruskal-Wallis tests). The difference between groups was especially important for the TK scores, in which the two youngest groups' scores were significantly higher (post-hoc tests). Other post-hoc multiple comparisons showed a significantly lower score for the oldest group (compared to 1,2, and 4) and lower TCK score of Group 4 compared to Group 2. There was no difference between age groups concerning the TPC scores.

Table 4: Seven factors' means among age groups (all the factors have been rescaled to be out of 100). The significance is based on Kruskal-Wallis chi-squared tests, completed by post-hoc Wilcoxon signed rank tests. 


\begin{tabular}{|c|c|c|c|c|c|c|c|c|}
\hline & \multirow[t]{2}{*}{$\mathrm{N}$} & \multicolumn{7}{|l|}{ Mean } \\
\hline & & $\mathrm{CK}$ & $\mathrm{PK}$ & PCK & $\mathrm{TK}$ & TPK & TCK & TPC \\
\hline 20-29 (1) & 41 & 78.39 & 76.83 & 72.25 & 77.13 & 73.31 & 71.89 & 71.94 \\
\hline $30-39$ (2) & 181 & 82.47 & 79.79 & 73.38 & 75.25 & 72.44 & 72.30 & 74.63 \\
\hline $40-49$ (3) & 189 & 83.30 & 80.63 & 73.63 & 70.50 & 69.75 & 69.22 & 71.75 \\
\hline $50-59(4)$ & 130 & 85.13 & 82.96 & 78.13 & 70.19 & 71.75 & 68.22 & 70.88 \\
\hline $60+(5)$ & 33 & 86.80 & 81.58 & 79.13 & 64.94 & 63.25 & 68.64 & 68.75 \\
\hline $\begin{array}{l}\text { p-value } \\
\text { Kruskal- } \\
\text { Wallis }\end{array}$ & & 0.025 & 0.089 & 0.018 & 0.000 & 0.011 & 0.019 & 0.031 \\
\hline $\begin{array}{l}\text { Post-hoc } \\
\text { Wilcoxon } \\
\text { signed } \\
\text { rank }\end{array}$ & & & & & $\begin{array}{l}1>3, p= \\
0.039 \\
1>4, p= \\
0.039 \\
1>5, p= \\
0.008 \\
2>3, p= \\
0.005 \\
2>4, p= \\
0.008 \\
2>5, p= \\
0.002\end{array}$ & $\begin{array}{l}1>5, p= \\
0.031 \\
2>5, p= \\
0.024 \\
4>5, p= \\
0.043\end{array}$ & $\begin{array}{l}2>4, p= \\
0.016\end{array}$ & \\
\hline
\end{tabular}

\subsubsection{Other demographic factors and the global influence of countries' contexts}

Two other demographic variables were tested according to the seven factors of the TPACK model: level of academic degree and gender. None of these comparisons revealed significant differences between tested groups. Moreover, a normalized TPACK score was computed and an ANOVA was performed on the four factors investigated in this study: age, level of academic degree, gender and country. The use of ANOVA was permitted since the conditions of this test were verified (normality, homoscedasticity and independence of residuals). For the normality a Shapiro test obtained $\mathrm{W}=0.99$ with the $\mathrm{p}$-value $=0.78$, for the homoscedasticity the BreuschPagan test obtained $\mathrm{BP}=19.05$ and $\mathrm{p}$-value $=0.09$ and for the independence Durbin Watson Test obtained $\mathrm{DW}=1.84$ with $\mathrm{p}$-value $=0.052$. The ANOVA showed that the country context has-a significant effect on the TPACK score ( $\mathrm{p}$-value $<0.001$ ). None of the other factors or interactions between factors revealed significant differences.

\section{Discussion}

\subsection{Findings}

1. The first major result regards the substantial validation of the seven-factor TPACK model across a sixcountry sample (research question 1).

The seven-factor model elaborated by Mishra and Koehler (2006) was supported by the results of the CFA. Other works were similar (Lin et al. 2013; Schmidt et al. 2009), showing consistency with the original seven- 
factor model in measuring perceptions of TPACK. The relative stability of the model structure across countries supports the relevance of using the seven-factor model when analysing cross-national surveys.

2. The second major result is the relative differences of university teachers' TPACK perceptions across six countries of Europe and Asia (research question 2).

The score differences for the seven TPACK factors were mainly related to the Bhutanese sample. If it was excluded, there were only a few differences in PCK, where France had a significantly higher score compared to Estonia and Pakistan, and in TPK, where Pakistan had a significantly higher score than France. There were no significant differences for the other factors. The score of the French university teachers regarding PCK can be attributed to the long tradition of the French didactique in teacher training. However, the low TPK score of the French sample which was significant compared to Pakistan, revealed a lagging technology integration in the French educational system, which has been admitted by the government (Karayan 2016). In the case of Bhutan, teacher education is faced with many issues, such as teachers' low professional esteem (VanBalkom and Sherman 2010), and there has already been a call for revamping the teacher preparation programmes to provide more pedagogical and content-related knowledge as well as more ICT facilities (Ministry of Education 2014; Sherab et al. 2017). Many years later, this trend is still relevant through TPACK perception which showed significantly lowest scores in PCK, TK, TPK, TCK, and TPC. However, in every country it is possible to notice a similar trend: $\mathrm{T}$-factors were usually less rated. This result clearly highlights the training need of teacher educators not only on using technology (TK) but also on how to use it to support content and/or pedagogical knowledge (TCK, TPK, and TPC). The ranking based on the "use sub-index" of the IDI (ICT development index) fits well for the Denmark and Estonia which had generally better scores on dimensions including technologies. However, for the other countries, it is not clear. In the case of Pakistan and Malaysian, teacher educators had comparable or even sometimes the best scores on dimension including technologies. This difference with the IDI is probably rooted into the important gap in Pakistan and Malaysia between the level of teacher educators and the public and probably a less important gap in Europe.

3. The third major result is the dependence of age on TPACK factors (research question 2).

The global comparisons of age-groups were almost all significant (except for PK scores), showing a clear relationship between age and perceptions of TPACK. However, the multiple pairwise comparisons failed to attain the statistical significance level. This a priori contradiction can be explained by the limit of the statistic and methodological approach. Indeed, the small sizes of Group 1 (the youngest) and Group 5 (the oldest) introduced a lack of statistical power less likely to detect significant differences. Another issue was the use of the Holm p-value adjustment to counteract the problem of multiple comparisons. Without any adjustment, it appeared that the level of significance was reached in many cases; for instance, the group of 30-39-year-old teachers had a higher significant TPC score compared to the three older groups. This adjustment came at the cost of increasing the type II error risk (not detecting the difference). However, much evidence converged in the sense that age and TPACK perceptions were strongly related, as suggested by Koh et al. (2010), Lee and Tsai (2010), and Lin et al. (2013). The recommendations that it can be formulated for the institutions involved into the research is to differentiate some teacher educators' training modules based on the specific lacks identified in each national context. Moreover, since age is another important factor influencing technology knowledge and how to integrate it into instruction, Learning Activity Types approach (Hofer and Harris 2010) for building TPACK and differentiating experimented and unexperimented teacher educators would be an interesting framework for developing teacher educators' TPACK. Nevertheless, the ANOVA based on the TPACK global scores (not on the different seven sub-scales), showed that the "country context" is the only significant factor. This result supports that compared to other factors (especially age which is significant for some specific TPACK dimensions) the country context is the most important factors explaining differences on the TPACK .

4. The fourth major result is the independence of gender and level of training from the TPACK factors (research question 2).

The results of the study also supported that there was no gender difference in the TPACK perception, in contrast with other works in which women demonstrated more difficulties with knowledge related to technology (Koh et al. 2010; Lin et al. 2013; Markauskaite 2006). In gender comparisons, context matters (Yoder and Kahn 2003): 
in previous studies were conducted in Singapore and in Australia, whereas this study sample was from Europe, Pakistan, Malaysia, and Bhutan. In the last few years policymakers and researchers have made efforts to bridge the gender gap (e.g.; Krämer et al. 2016; Reilly et al. 2017; Wang and Degol 2017). The question therefore relates to whether the first effects of these new teaching strategies can be observed in this study?

The absence of differences between the educators' initial level of training can be explained by the presence, in all the institutions, of skills development programmes contributing to the development of teaching capacities of the university staff. Thus, the lifelong training and skills development programmes allowed by universities contribute to reduce the professional skill differences among teacher educators.

\subsection{Study limitations}

The data collection was performed while trying to respect a sampling protocol. However, in some groups the number of participants was lower than expected. Since the sample size was low, it was difficult to detect significant differences in some instances; for example, detecting differences between the Estonian and Danish groups could be a limiting factor. Nevertheless, some differences were detected between the other countries, illustrating the context dependence of the TPACK levels of teacher educators. The current comparison study was limited using two versions of the questionnaire, one in French and one in English. Hence, a risk of concept mistranslation had been introduced decreasing the validly of comparisons. However, reasonable translation precautions (translation and backtranslation process) have been taken in order to limit this bias. Since all the Asian countries of this study adopt English as an official language, the choice of using the English version even in Estonia and in Denmark where English is not an official national language was made. However, the good level in English of those sampled populations, the habit of having English information disseminated by their institutions and the "easy-answer" questionnaire provided confidence in the validity of the results obtained. 


\section{References}

Archambault, L. M., \& Barnett, J. H. (2010). Revisiting technological pedagogical content knowledge: Exploring the TPACK framework. Computers \& Education, 55(4), 1656-1662.

Baturay, M. H., \& Toker, S. (2015). An investigation of the impact of demographics on cyberloafing from an educational setting angle. Computers in Human Behavior, 50, 358-366.

Benson, S. N. K., \& Ward, C. L. (2013). Teaching with technology: Using TPACK to understand teaching expertise in online higher education. Journal of educational computing research, 48(2), 153-172.

Bentler, P. M. (1990). Comparative fit indexes in structural models. Psychological bulletin, 107(2), 238.

Benton-Borghi, B. H. (2013). A Universally Designed for Learning (UDL) infused Technological Pedagogical Content Knowledge (TPACK) practitioners' model essential for teacher preparation in the $21 \mathrm{st}$ Century. Journal of educational computing research, 48(2), 245-265.

Browne, M. W., \& Cudeck, R. (1993). Alternative ways of assessing model fit. Sage focus editions, 154, 136136.

Bueno-Alastuey, M. C., Villarreal, I., \& García Esteban, S. (2018). Can telecollaboration contribute to the TPACK development of pre-service teachers? Technology, Pedagogy and Education, 1-14.

Byker, E. J., Putman, S. M., Polly, D., \& Handler, L. (2018). Examining Elementary Education Tearchers and Preservice Teachers' Self-Efficacy Related to Technological Pedagogical and Content Knowledge (TPACK). In C. B. Hodges (Ed.), Self-Efficacy in Instructional Technology Contexts (pp. 119-140). Statesboro, GA, USA: Springer.

Cangur, S., \& Ercan, I. (2015). Comparison of model fit indices used in structural equation modeling under multivariate normality. Journal of Modern Applied Statistical Methods, 14(1), 14.

Cengiz, C. (2015). The development of TPACK, technology integrated self-efficacy and instructional technology outcome expectations of pre-service physical education teachers. Asia-Pacific Journal of Teacher Education, 43(5), 411-422.

Chai, C. S., Ng, E. M., Li, W., Hong, H.-Y., \& Koh, J. H. (2013). Validating and modelling technological pedagogical content knowledge framework among Asian preservice teachers. Australasian Journal of Educational Technology, 29(1).

Chang, Y., Jang, S. J., \& Chen, Y. H. (2015). Assessing university students' perceptions of their P hysics instructors' TPACK development in two contexts. British Journal of Educational Technology, 46(6), 1236-1249.

Chen, Y.-H., \& Jang, S.-J. (2018). Exploring the Relationship Between Self-Regulation and TPACK of Taiwanese Secondary In-Service Teachers. Journal of educational computing research, 0735633118769442.

Chevallard, Y. (1985). La transposition didactique : du savoir savant au savoir enseigné. Grenoble La Pensée sauvage.

Cubeles, A., \& Riu, D. (2018). The effective integration of ICTs in universities: the role of knowledge and academic experience of professors. Technology, Pedagogy and Education, 1-11.

Griffiths, M. D., Davies, M. N., \& Chappell, D. (2004). Demographic factors and playing variables in online computer gaming. CyberPsychology \& behavior, 7(4), 479-487.

Guo, R. X., Dobson, T., \& Petrina, S. (2008). Digital natives, digital immigrants: An analysis of age and ICT competency in teacher education. Journal of educational computing research, 38(3), 235-254.

Harris, J. B., \& Phillips, M. If There's TPACK, is There Technological Pedagogical Reasoning and Action? In Society for Information Technology \& Teacher Education International Conference, 2018 (pp. 20512061): Association for the Advancement of Computing in Education (AACE)

Hofer, M. J., \& Harris, J. B. Differentiating TPACK development: Using learning activity types with inservice and preservice teachers. In Society for Information Technology \& Teacher Education International Conference, 2010 (pp. 3857-3864): Association for the Advancement of Computing in Education (AACE)

Hofer, M. J., \& Harris, J. B. Differentiating TPACK-based learning materials for preservice and inservice teachers. In Society for Information Technology \& Teacher Education International Conference, 2017 (pp. 2357-2366): Association for the Advancement of Computing in Education (AACE)

Holm, S. (1979). A simple sequentially rejective multiple test procedure. Scandinavian journal of statistics, 6570.

Joo, Y. J., Park, S., \& Lim, E. (2018). Factors influencing preservice teachers' intention to use technology: TPACK, Teacher Self-efficacy, and Technology Acceptance Model. Journal of Educational Technology \& Society, 21(3), 48-59. 
Karayan, R. (2016). Najat Vallaud-Belkacem: "Le retard français dans l'école numérique a été utile". https://www.lexpress.fr/education/najat-vallaud-belkacem-le-retard-francais-dans-l-ecole-numerique-aete-utile 1806654.html. Accessed 25/06/2018 2018.

Khatoon Malik, S., \& Tanzeela, U. (2012). Status of teacher education in Pakistan- A problem centered approach. Elixir Leadership Management, 46, 8581-8586.

Khine, M. S., Ali, N., \& Afari, E. (2017). Exploring relationships among TPACK constructs and ICT achievement among trainee teachers. Education and Information Technologies, 22(4), 1605-1621.

Koehler, M. J., \& Mishra, P. (2005). Teachers learning technology by design. Journal of computing in teacher education, 21(3), 94-102.

Koehler, M. J., \& Mishra, P. (2009). What is technological pedagogical content knowledge (TPACK)? Contemporary Issues in Technology and Teacher Education, 9(1), 60-70.

Koehler, M. J., Mishra, P., Hershey, K., \& Peruski, L. (2004). With a little help from your students: A new model for faculty development and online course design. Journal of Technology and Teacher Education, 12(1), 25.

Koehler, M. J., Mishra, P., \& Yahya, K. (2007). Tracing the development of teacher knowledge in a design seminar: Integrating content, pedagogy and technology. Computers \& Education, 49(3), 740-762.

Koh, J. H. L., Chai, C. S., \& Tsai, C.-C. (2010). Examining the technological pedagogical content knowledge of Singapore pre- service teachers with a large- scale survey. Journal of Computer Assisted Learning, 26(6), 563-573.

Krämer, N. C., Karacora, B., Lucas, G., Dehghani, M., Rüther, G., \& Gratch, J. (2016). Closing the gender gap in STEM with friendly male instructors? On the effects of rapport behavior and gender of a virtual agent in an instructional interaction. Computers \& Education, 99, 1-13.

Lee, M.-H., \& Tsai, C.-C. (2010). Exploring teachers' perceived self efficacy and technological pedagogical content knowledge with respect to educational use of the World Wide Web. Instructional Science, $38(1), 1-21$.

Lin, T.-C., Tsai, C.-C., Chai, C. S., \& Lee, M.-H. (2013). Identifying Science Teachers' Perceptions of Technological Pedagogical and Content Knowledge (TPACK). [journal article]. Journal of Science Education and Technology, 22(3), 325-336, doi:10.1007/s10956-012-9396-6.

Luik, P., Taimalu, M., \& Suviste, R. (2018). Perceptions of technological, pedagogical and content knowledge (TPACK) among pre-service teachers in Estonia. Education and Information Technologies, 23(2), 741755 .

Manerikar, V., \& Manerikar, S. (2015). Cronbach's alpha. A Peer review research journal. aWEshkar WeSchool, 19(1), 117-119.

Markauskaite, L. (2006). Gender issues in preservice teachers' training: ICT literacy and online learning. Australasian Journal of Educational Technology, 22(1), 1.

Ministry of Education (2014). Bhutan education blueprint (2014-2024): Rethinking education. Thimphu: Ministry of Education.

Mishra, P., \& Koehler, M. J. (2006). Technological pedagogical content knowledge: A framework for teacher knowledge. Teachers college record, 108(6), 1017.

Niess, M. L. (2011). Investigating TPACK: Knowledge growth in teaching with technology. Journal of educational computing research, 44(3), 299-317.

Puentedura, R. (2013). SAMR and TPCK : An Introduction. http://www.hippasus.com/rrpweblog/archives/2013/03/28/SAMRandTPCK_AnIntroduction.pdf. Accessed 10/07/2019 2019.

Reilly, D., Neumann, D. L., \& Andrews, G. (2017). Gender differences in spatial ability: Implications for STEM education and approaches to reducing the gender gap for parents and educators. In Visual-spatial Ability in STEM Education (pp. 195-224): Springer.

Scherer, R., Tondeur, J., \& Siddiq, F. (2017). On the quest for validity: Testing the factor structure and measurement invariance of the technology-dimensions in the Technological, Pedagogical, and Content Knowledge (TPACK) model. Computers \& Education, 112, 1-17.

Schermelleh-Engel, K., Moosbrugger, H., \& Müller, H. (2003). Evaluating the fit of structural equation models: Tests of significance and descriptive goodness-of-fit measures. Methods of psychological research online, 8(2), 23-74.

Schmidt, D. A., Baran, E., Thompson, A. D., Mishra, P., Koehler, M. J., \& Shin, T. S. (2009). Technological pedagogical content knowledge (TPACK) the development and validation of an assessment instrument for preservice teachers. Journal of Research on Technology in Education, 42(2), 123-149.

Schmidt, D. A., \& Gurbo, M. (2008). TPCK in K-6 literacy education: It's not that elementary. Handbook of technological pedagogical content knowledge (TPCK) for educators, 61-85. 
Sherab, K., Bidha, S., Khorlo, T., Wangchuk, U., \& Rinzin, R. (2017). Efficacy of the Four-Year B. Ed Primary Programme at Paro College of Education. Paro: Paro College of Education, Royal University of Bhutan.

Shulman, L. (1987). Knowledge and teaching: Foundations of the new reform. Harvard educational review, 57(1), 1-23.

Tanaka, J. S., \& Huba, G. J. (1985). A fit index for covariance structure models under arbitrary GLS estimation. British Journal of Mathematical and Statistical Psychology, 38(2), 197-201.

VanBalkom, W. D., \& Sherman, A. (2010). Teacher education in Bhutan: highlights and challenges for reform. Asia Pacific Journal of Education, 30(1), 43-55.

Voogt, J., \& McKenney, S. (2017). TPACK in teacher education: are we preparing teachers to use technology for early literacy? Technology, Pedagogy and Education, 26(1), 69-83, doi:10.1080/1475939X.2016.1174730.

Wang, M.-T., \& Degol, J. L. (2017). Gender gap in science, technology, engineering, and mathematics (STEM): Current knowledge, implications for practice, policy, and future directions. Educational psychology review, 29(1), 119-140.

Wheaton, B., Muthen, B., Alwin, D. F., \& Summers, G. F. (1977). Assessing reliability and stability in panel models. Sociological methodology, 8, 84-136.

Yaghi, H. M. (2001). Subject matter as a factor in educational computing by teachers in international settings. Journal of educational computing research, 24(2), 139-154.

Yoder, J. D., \& Kahn, A. S. (2003). Making gender comparisons more meaningful: A call for more attention to social context. Psychology of Women Quarterly, 27(4), 281-290. 